\title{
The technofossil record of humans
}

\author{
Jan Zalasiewicz1, Mark Williams', Colin N. Waters², Antony D. Barnosky ${ }^{3}, 4,5$, \\ Peter Haff6
}

1. Department of Geology, University of Leicester, University Rd., Leicester LE1 7RH, UK.

2. British Geological Survey, Keyworth, Nottingham, NG12 5GG, UK.

3. Department of Integrative Biology, University of California, Berkeley, California 94720, USA.

4. University of California Museum of Paleontology, California, USA.

5. University of California Museum of Vertebrate Zoology, California, USA.

6. Nicholas School of the Environment, Division of Earth and Ocean Sciences, Duke University, Durham, North Carolina, 27516, USA

\begin{abstract}
As humans have colonised and modified the Earth's surface, they have developed progressively more sophisticated tools and technologies. These underpin a new kind of stratigraphy, that we term technostratigraphy, marked by the geologically accelerated evolution and diversification of technofossils - the preservable material remains of the technosphere (Haff, 2012), driven by human purpose and transmitted cultural memory, and with the dynamics of an emergent system. The technosphere, present in some form for most of the Quaternary, shows several thresholds. Its expansion and trans-continental synchronisation in the mid twentieth century has produced a global technostratigraphy that combines very high time resolution, great geometrical complexity and wide (including trans-planetary) extent. Technostratigraphy can help characterize the deposits of a potential Anthropocene Epoch and its emergence marks a step change in planetary mode.
\end{abstract}

Keywords: Anthropocene, stratigraphy, technology, human artefacts

\section{Introduction}

From the beginnings of geology, fossils have been recognised as central to the science, not only because they are a record of life (the most important feature of our planet) but because biological evolution has provided a means of dating and correlating strata, and hence underpinning the Geological Time Scale. Thus, the Phanerozoic Eon (roughly, the last half-billion years of Earth history) was characterised by complex metazoans with hard skeletal parts. It has a finely resolved time scale largely founded on fossil zones, reflecting the evolution of these organisms. In this way, Phanerozoic time can be split into intervals that may be less than a million years in duration, for example exploiting the evolution 
of graptolites (extinct colonial plankton) in strata of the Ordovician and Silurian periods, of ammonites in the Jurassic, and of mammals in the Cenozoic. The Precambrian (that is, pre-Phanerozoic time), some four billion years in duration, retains a cruder time scale still largely based on arbitrary numerical time divisions (Gradstein et al., 2012).

In more recent geological times, of the later Tertiary and Quaternary periods, other means of correlation have been used, such as magnetostratigraphy and cyclostratigraphy, that exploit changes in the Earth's magnetic field and in its spin and orbit respectively (Cande \& Kent, 1992; Pälike et al., 2006; Wade et al., 2011). These have provided the highest time-resolution, locally to millennial scale, and in the best cases of ${ }^{14} \mathrm{C}$ dating, to the decadal (or in some cases even of annual/seasonal) scale. By comparison, late Tertiary/Quaternary biostratigraphic divisions based upon appearances and extinctions of various species provide relatively coarser subdivision than such other means of dating. In this interval, biostratigraphy, especially on land, mostly reflects local patterns of species immigration and emigration driven largely by climate change, that were in turn driven by the astronomical variations. (There have, though, been some notable extinctions, particularly of large mammal species over the past 11 millenia, likely at least in part through overkill by early hunters: Martin \& Klein 1984).

However, for time periods since the evolution of humans during the Quaternary, new ways to use fossils as geological time markers have arisen. These are largely the physical objects devised and made by species of humans beginning at least 2.5 Myr ago (Kimbel et al., 1995; Ambrose, 2001). Changes in these artefacts have been driven by cultural, not biological, evolution. Using tools is not quite singular to humans, limited examples being provided by other species such as apes and crows (Van Lawick-Goodall, 1970) but humans have taken tool production to levels of sophistication that are without precedent in the history of life. The study of human-produced artefacts has been largely the province of archaeologists and, for more recent years, historians (using that term in its widespread meaning of referring to human rather than natural history: Chakrabarty, 2009). Because human colonisation of Earth has for most of history been local, patchy and of low density, artefacts are sporadically distributed (though locally common) and reflect local cultural development. Nevertheless, the artefacts can be used to date sedimentary deposits and so help constrain the timing of events in natural history. For example, the Palaeolithic, Mesolithic, and Neolithic, each referring to successively younger stages of development (albeit globally diachronous ones), are defined and recognized by the presence of certain tool kits.

With the explosive growth in human numbers since around the end of the $18^{\text {th }}$ century, associated with and reflecting the increased exploitation of energy, mainly steam in the $19^{\text {th }}$ century and largely hydrocarbons in the $20^{\text {th }}$ century, there has been an orders-of-magnitude increase in the production of human artefacts, as outlined by such measures as the PAT [population $\mathrm{x}$ affluence $\mathrm{x}$ technology] scale (e.g. Steffen et al., 2012), especially since the 'Great Acceleration' (Steffen et al., 2007) of the mid-twentieth century. This has been 
accompanied by acceleration in the rate of technological evolution (and hence in the rate of appearance of different types of artefacts) and by globalization, which has spread these artefacts around the Earth, making them consistently transregional rather than diachronous or local time markers.

All of these objects may be considered in general as ichnofossils (trace fossils), as suggested by Ford et al. (in press), Barnosky (in press), Zalasiewicz et al. (in press a) and others. As such, they have the capacity to characterise and date the enclosing sedimentary deposits, complementing the data provided by more conventional organic remains (Barnosky, in press; Wilkinson, in press). However, these particular human-made phenomena have several quite distinctive characteristics, which serve to separate them from trace fossils as normally understood. Hence, we distinguish them here as technofossils, a biological innovation which may be exploited to provide ultra-high resolution geological dating and correlation in technostratigraphy, after the concept of the technosphere proposed by Haff (2012).

In this paper, we outline the distinctive nature of the biostratigraphic information provided by technofossils, discuss its novel aspects, and explore how this may be of use to help characterise the deposits of a potential Anthropocene Epoch (Crutzen, 2002; Zalasiewicz et al., 2008; Williams et al., 2011; Waters et al. in press), much as previous biological innovations provide the material and conceptual basis for characterising the geological eras, periods, and ages that have been assembled as the Geological Time Scale (Williams et al., in press). We note, too, the wider significance of this phenomenon to Earth history.

\section{Human artefacts as technofossils: composition and form}

\section{Composition}

The origin and diversification of metazoans having produced relatively few new mineral types over and above inorganic mineral species (Hazen et al., 2008). Non-human fossils, both body and trace, tend to be made of a limited number of materials that are specific to the species: thus molluscan body fossils are of mostly of calcium carbonate (either aragonite or calcite) while vertebrate ones are typically of apatite or its diagenetic derivatives. Non-human trace fossils tend to be yet more limited, being either impressions in sediment (molds), sediment-filled holes (casts), or in rare cases made of selected local clasts as in the case of some solitary wasp nests (Ratcliffe \& Fagerstrom, 1980). Some diversity of composition can be found in the case of trace fossils secreted with specific compositions (spider-web silk and honey-comb wax), excreted (rock hyrax latrines : Chase et al., 2012) or gathered (packrat middens). In all of these cases, however, the diversity of composition consists almost exclusively of organic materials.

Humans, by contrast, produce artefacts from materials that are either very rare in nature (uncombined iron, aluminium and titanium) or unknown naturally (uncombined vanadium, molybdenum). There is a wide variety of novel 
minerals such as boron nitride, tungsten carbide and, and 'mineraloids' such as artificial glasses and plastics (Zalasiewicz et al., in press b). The number of these novel materials continues to grow.

Where sufficiently common, widely distributed and preservable, these component materials themselves may be used in themselves as fossil indicators of time (Ford et al., in press; Zalasiewicz et al., in press). Modern plastics such as polyethylene and polypropylene are essentially a post-World War II phenomenon; their current global production is 270 million tons a year (Rochman et al., 2013), sufficient to cover the USA in a layer of standard kitchen cling-film (=plastic wrap). The total production of aluminium metal, also virtually all since 1950, is at least 500 million tons (Zalasiewicz et al., in press b). The distribution of these materials is patchy, with densest concentrations in landfill sites and recycling and combustion plants. However, there is sufficient escape, essentially as litter, for these to be common elements of both marine (marine rubbish gyres and fragments in sediments) and terrestrial sedimentary environments, and thus to be time markers in recent, current and near-future deposits.

Novel and natural minerals commonly combine into anthropogenic lithologies. These include concrete (annual production 3.4 billion tons and rising: Amato, 2013), bricks, mortar/cement, breeze-block material, road metal ('tar macadam'), ceramics and so on. As with the minerals, these have evolved in type and amount in tandem with human cultural development. Particularly since the mid-twentieth century, and the growth of urban areas in developing countries, they have become more globally widespread (Ford et al., in press).

Form

Minerals (considered sensu lato, including organogenic materials such as paper and textiles) and rocks, both natural and artificial, are combined in a diversity of patterns to produce the diverse and changing range of technofossils, that range in scale from the near-continental urban conglomerations) to small (e.g. bottles, pens) to microscopic (e.g. fly ash particles). Some are fixed to the ground surface (buildings and roads), others are not fixed (cups, books) while yet others are built for long-distance travel (cars, aeroplanes) that may even extend beyond this planet (spacecraft). All that are preservable (see below) in the short term (decades/centuries) can help characterize Anthropocene deposits for presentday Earth scientists, while all that are preservable over geological time-scales will contribute to the 'far-future' signal of the Anthropocene.

The morphological range of technofossils is almost infinitely greater than the range of trace types produced by any other species. Most trace fossil-formers produce a single type of trace, though some may produce a small number of different types (e.g. trilobite species that produce at different times both Cruziana walking traces and Rusophycus resting traces). The number of different types of potentially preservable human artefacts, by contrast, numbers in the millions, as a result of cultural evolution, and is growing daily. 


\section{Rate of evolution of technofossils}

Early in hominid history, technofossil evolution roughly reflected the pace of human evolution. Since the appearance of Homo sapiens, the two have been largely decoupled. Through the time of Homo sapiens on Earth, some 200,000 years, the general trend has been for the rate of evolution of technofossils to increase.

Thus, in the late Pleistocene to early Holocene, discernable changes in technologies were accomplished in millennia - e.g. from Stone Age, to Bronze Age to Iron Age. Within most human communities, the technology produced during (and therefore the material life of) one generation was very much like that of another. This was particularly pronounced in small hunter-gatherer communities (where technologies stayed much the same, even towards the present day.

With the development of large settled, agrarian communities, technofossil development speeded up - though even here, some large agrarian communities, such as those of the ancient Egyptians, remained relatively conservative in this respect. Subsequently, over most of the last 2-3 millennia, technofossil evolution was more rapid, although patchily distributed globally, with distinct episodes of more rapid cultural and technological evolution among particular communities (e.g. the Ancient Greek and Roman cultures of the western European and Mediterranean region from the $8^{\text {th }}$ century $\mathrm{BC}$ to $476 \mathrm{AD}$, and then, as progress stalled in this region during the Dark Ages, there were advances in north Africa and China). The Renaissance in Europe was another key phase of acceleration. Then, came the Industrial Revolution and its transmission to other parts of the world over the $19^{\text {th }}$ century. With that, the items made and used by humansand the resulting technofossils--began to markedly change from one generation to the next. From the mid-twentieth century onwards, the changes were globally synchronized and sufficiently rapid for social commentators to write of 'future-shock' experienced not only between, but within human generations (Toffler, 1970). For example, the generation that lived from the early to late 1900s saw transportation change from horses to automobiles to airplanes to rockets and communication change from hand-delivered letters, to telegraph, to land-line telephones, to e-mail and mobile phones. All of these changes are clearly reflected in the technofossil record.

The accelerating pace of technofossil evolution correlated strongly with increases in population, not only globally, but also within specific cultures. It is in direct contrast to the pattern classically seen in biological evolution, where the most rapid evolution typically occurs in small isolated populations, with larger populations remaining more stable (e.g. Mayr, 1942).

Current evolution of the technosphere, of which the technofossils are the preserved remnant, is hence now orders of magnitude faster than biological evolution. The rate of technospheric evolution corresponds in part with increased human numbers and energy expenditure, together with enhanced cultural evolution through institutional means, such as expanded university and 
training systems. But, there are clearly further factors at work. One is exponentially increasing technical possibilities founded on earlier advances, and the multiplying potential cross-links between them, acting in positive (and accelerating) feedback systems.

\section{Distribution and preservation}

With acceleration of technofossil evolution has come increase in geographical distribution. Technofossil evolution correlates in part with human population, with increased energy and material use, and increased globalization, the resulting stratigraphic signal within recent strata, hence, is growing increasingly distinct. While artefacts of the past millennia largely reflected local to regional cultures, post-WWII times have seen the spread of, to take just a few out of many examples, paper-clips, aluminium cans, ball-point pens and plastic bags over every continent, and spilling over into the marine realm. The human trace fossils are facies-controlled, as are the fossils in ancient strata. They are more typical of terrestrial settings, especially in and around urban regions, but they have spread widely into rural and 'wilderness' regions, too. Their spread into the marine environment is now significant, both from being washed in from land and being transported into deep water via shipping traffic (Ramirez-Llodra, 2011), as well as via the ebb surge currents following major storms and tsunami.

The abundance of technofossils reflects great current differences between the technosphere and biosphere as regards recycling of its component matter. Many biological systems (e.g. tropical forests) recycle virtually all of their component matter, the decay-related entropy increase being balanced by solar energy input to recreate and maintain complex organic systems. Even where component matter accumulates into organic-rich sediments, typical percentages of production sequestered are less than $1 \%$, and so in many strata fossils are rare. In the contemporary technosphere, by contrast, recycling rates are much lower (e.g. $\sim 50 \%$ for aluminium, $<20 \%$ for plastics, $<10 \%$ for concrete). Detritus from the technosphere is hence abundantly disseminated.

The preservation of technofossils reflects conditions of burial (many are buried actively, e.g. in landfills) and of the subterranean environment, as they undergo various degrees of alteration. Information regarding the preservability of various 'tissues/artefacts' may be partly derived from knowledge of how fossils are preserved, and partly from study of the condition of archaeological remains, though an increasing number of modern materials and artefacts have few direct analogues either in palaeontology or in archaeology. Much, though, is poorly digestible for scavenging metazoa and microbes, too (e.g. plastics, metals - even wood is commonly seasoned or varnished to resist decay). Technofossils, particularly from their expansion in production of the last few decades, are unlikely to be rare.

The physical degradation of anthropogenic deposits with time may result from erosion or the alteration of the deposit with rates of diagenesis controlled, as with natural sediments, by moisture content, temperature, redox potential and $\mathrm{pH}$. Seemingly robust materials such as bricks or concrete may degrade in the presence of water, temperature fluctuations and sulphate- or chloride-rich 
groundwaters, iron-based metals can corrode in the presence of oxygen and chloride ions, and plastics degrade in the presence of light, oxygen, heat or corrosive fluids (Ford et al. in press). However, leachates sourced from these altered deposits, notably rich in calcium carbonate sourced from degraded cement, concrete or plaster, may produce cements that can ultimately bind and solidify deposits.

The last century, too, has seen the extension of humans to great depths in the crust, as mining activities commonly reach hundreds of metres into the ground, and drilling operations penetrate to several thousands of metres. This deep crustal penetration by the metazoan biosphere is without precedent in Earth history. Simultaneously, human-made structures have invaded the skies and even outer space, to reach other planets and moons of this star system. In the translation of this contemporary phenomenon to stratigraphy, the deep crustal traces have extremely high preservation potential (until the rocks affected are carried to the surface and eroded, or until they are affected by mountainbuilding processes so that borehole traces, for example, are obliterated by highgrade metamorphism). The constructions that travel through the atmosphere, by contrast, are only rarely preservable, for instance as aeroplanes that crash into the sea. In the case of extra-terrestrial satellites and landing-craft, some are now distributed among other planets and moons (those on our Moon, at least, having also very high preservation potential), which again marks a new transition in the history of not just the Earth, but of the Solar System.

\section{Technofossil nomenclature}

Trace fossils, like body fossils, may be classified using standard Linnean binomial nomenclature, as ichnospecies. However, using this approach with technofossils (i.e. by reference to the trace-maker, as Homo sapiens ichnosp.) is clearly of little help in distinguishing between the many types of individual traces.

Some broad categories may be equated with those applied to ichnofossils following the widely used classification of Seilacher (1964); thus, as traces that are locomotory, resting, dwelling, feeding and so on. Many if not most human artefacts could likely be classified thus. Thus, implements ranging from stone tools to steel knives and electric food mixers could be identified as for killing and processing food, and be feeding traces (pascerichnia). Buildings from the most primitive huts to skyscrapers could be housing traces, i.e. domichnia. Roads and airport runways (and cars and aeroplanes) could be locomotion traces, or repichnia.

The range and diversity of technofossils means that one could indulge in fine taxonomic 'splitting' and hierarchical categorization of the artefacts in terms of morphology and function. For instance, a toothbrush may be regarded as one type of artefact, within a wider category of brushes and brooms. Collectively, these are all cleaning traces. In detail, thousands of different types of toothbrushes have been produced. The range of diversity rivals biological diversity - but ichnological characterization of this sort may complement 
standard archaeological, historical and everyday vernacular categorization to provide useful insights. For instance, while some categories of traces may have clear ichnological (and therefore wider biological) counterparts, others may be more or less uniquely human - for instance, the technofossils that we build for recreation (tennis rackets, concert halls), and where novel categories may be needed.

\section{Technostratigraphic classification}

Just as the classification of the technofossils themselves merits careful consideration to encompass the enormous, and growing, diversity of these phenomena, so does their formal exploitation in biostratigraphic classification.

In palaeontology, the range and diversity of fossilizeable organisms is simplified to produce a limited number of temporal divisions, often based on the most common, widespread and distinctive of the fossils. Thus, in the Silurian, biostratigraphic zonation is largely based upon graptolites, conodonts, chitinozoans, acritarchs and brachiopods (Melchin, 2012), with the most important divisions being those where new grades of organisation are attained (such as the origin of monograptid graptolites). Other types of fossil (even common ones such as corals, trilobites and nautiloids) do not have widely employed zonations, although their recognition in strata may be used to constrain geological age.

Similarly, the recognition of technostratigraphic zones may depend upon common technofossils, and newly achieved grades of organisation. We suggest that the incoming of certain materials (e.g. mass-produced plastics and aluminium) and the objects made from them (cans, bags) may provide useful marker levels. Given the rate of technological progress, technostratigraphic divisions may encompass as little as a decade. The middle of the $20^{\text {th }}$ century has seen a change from local techostratigraphies to, essentially, a global one, enhancing the potential of this time level (Wolfe et al., 2013; Waters et al., in press) as an appropriate and perhaps formal Anthropocene beginning. Within this, evolutionary appearances and extinctions (particularly the latter) clearly do not have the finality of their biological equivalents (consider long-playing vinyl records, now making something of a comeback following their virtual disappearance two decades ago). Nevertheless, the scale and rate of technostratigraphic change has produced abundant, preservable and effectively exploitable evidence of the passage of time, particularly when first-appearance datums are considered.

\section{The future of technofossil evolution}

Human traces clearly differ in several major respects from traditional ichnofossils, that are characterised by a narrow morphological ranges predetermined by genetic control. The extraordinary diversity of human artefacts (linked to the activities of just one species), rate of morphological 
evolution, and the acceleration in the rate of this change are without precedent in the Earth's geological record. Hence our suggestion that these represent a new category of fossil: technofossils, the preserved remains of the technosphere of Haff (2012) and the basis for technostratigraphy, for ultra-high resolution dating and correlating of strata, concerned with a putative Anthropocene time interval. They clearly reflect specific qualities that so far are unique to their initiating force, Homo sapiens.

The technosphere comprises the interconnecting technological systems that underpin modern human civilization (Haff, 2012), and is a phenomenon that has now reached a scale sufficient to perturb the natural physical, chemical and biological cycles of the Earth (Röckstrom et al., 2010) and provoke the suggestion of an Anthropocene Epoch (Crutzen, 2002).

The continued development of the technosphere and of the technostratigraphic imprint on Earth, currently depends on the continued success of Homo sapiens on Earth. However, the technosphere, although clearly currently mediated through human agency, has a dynamic of its own, cannot be said to be under any central human control. Further, as the complex system representing contemporary global economic networks, it is prone to unpredictable systemic failure (cf. Helbing, 2013). The resultant technostratigraphy, hence, may follow the catastrophist trajectory envisaged for Earth history by the $19^{\text {th }}$ century savant Baron Cuvier, rather than the gradualist progression later proposed by Charles Lyell. With the development of artificial intelligence and self-repair systems, some degree of extra-human autonomy may be appearing, and the emergence of self-replicating 'von Neumann' machines cannot be ruled out. In any event, continued technospheric evolution is set to produce new and distinct, short-lived technofossil assemblages that will succeed the present ones, to result in greater and geologically more long-lasting technostratigraphic change.

Given its central role in ongoing global change, not least in the perturbation of mass and energy flows, the emerging technosphere, if sustained, may represent the most fundamental revolution on Earth since the origin of the biosphere. The technofossil assemblages shed from it chart a step change in planetary mode.

\section{Acknowledgements}

CNW publishes with the permission of the Director, British Geological Survey. Simon Price and Jon Ford are thanked for their comments on an earlier version of this manuscript.

\section{References}

Amato, I. (2013) Concrete solutions. Nature 494: 300-301.

Ambrose, S.H. (2001) Paleolithic technology and human evolution. Science 291: 1748-1753. 
Barnosky, A. D.. in press. In: Palaeontological evidence for defining the Anthropocene. Waters et al. (eds). Geological Society Special Publication.

Cande, S. C., \& Kent D. V. (1992) A new geomagnetic polarity time scale for the Late Cretaceous and Cenozoic. Journal of Geophysical Research 97(B10): 1391713951, doi:10.1029/92JB01202.

Chakrabarty, D. (2009) The climate of history: four theses. Critical Inquiry 35 (Winter 2009): 197-222.

Chase, B M. , Scott, Louis., Meadows, M E., Gil-Romera, G., Boom, A, Carr, A S, Reimer, P J. , Truc, L, Valsecchi, V, and Quick. L J. (2012) Rock hyrax middens : a palaeoenvironmental archive in southern African drylands. Quaternary Science Reviews 56: 1-19.

Crutzen, P J. (2002) Geology of Mankind. Nature 415: 23.

Ford, J.R., Price, S.J., Cooper, A.H. \& Waters, C.N. (in press). An assessment of lithostratigraphy for anthropogenic deposits. In Waters, C.N., Zalasiewicz, J., Williams, M. et al. (Eds.) A Stratigraphical Basis for the Anthropocene. Geol. Soc. London, Spec. Publ.

Gradstein, F. M., Ogg, J. G., Schmitz, M. D. \& Ogg, G. M. (2012) A geologic time scale 2012. Vol. 1. Elsevier BV, Oxford, 436p.

Haff, P.K. (2010) Hillslopes, rivers, plows, and trucks: mass transport on Earth's surface by natural and technological processes. Earth Surface Processes and Landforms, 35, 1157-1166, doi: 10.1002/esp.1902.

Haff, P.K. (2012) Technology and human purpose: the problem of solids transport on the Earth's surface. Earth System Dynamics 3: 417-431.

Hazen, R.M., Papineau, D., Bleeker, W., Downs, R.T., Ferry, J.M., Mccoy, T.J., Sverjensky, D.A., Yang, H. (2008) Mineral evolution. American Mineralogist 93: 1639-1720.

Helbing, D. (2013) Globally networked risks and how to respond. Nature 497: 51-59.

Kimbel, W.H., Walter, R.C., Johanson, D.C., Reed, K.E., Aronson, J.L., Asefa, Z., Marean, C.W., Eck, G.G., Bobe, R., Hovers, E., Rak, Y., Vondra, C., Yemane, T., York, D., Chen, Y., Evensen, N.M. \& Smith, P.E. (1996) Late Pliocene Homo and Oldowan tools from the Hadar Formation (Kada Hadar Member), Ethiopia. Journal of Human Evolution 31: 549-561.

Martin, P.S. \& Klein, R.G. (eds) 1984. Quaternary extinctions. The University of Arizona Press. 
Mayr, E. (1942) Systematics and the origin of species. Columbia University Press, New York.

Melchin, M.J., Sadler, P.M. \& Cramer, B.D. (2012) The Silurian Period. Chapter 21 (pp. 526-558) in A Geological Time Scale 2012 (ed. Gradstein, F., OGG, G., Schmitz, M. \& OGG, G.). Elsevier, 1144 pp.

Pälike, H., Norris, R. D., Herrle, J. O., Wilson, P. A., Coxall, H. K., Lear, C. H., Shackleton, N. J., Tripati, A. K. \& Wade, B. S. (2006) The Heartbeat of the Oligocene Climate System. Science 314: 1894-1898.

Ramirez-Llodra, E., Tyler, P.A., Baker, M.C., Bergstad, O.A., Clark, M.R., Escobar, E., Levin, L.A. Menot, L., Rowden, A.A., Smith, C.R. \& Van Dover, C.L. (2011) Man and the Last Great Wilderness: Human Impact on the Deep Sea. Plos One 6 (8): e22588, 1-25.

Ratcliffe, B C \& Fagerstrom, J A. (1980) Invertebrate Lebensspuren of Holocene Floodplains: Their morphology, origin and paleoecological significance. Journal of Paleontology 54 (3): 614-630.

Rochman, C., Browne, M.A., Halpern, B.S., Hentschel, B.T., Hoh, E., Karapanagioti, H.K., Rios-Mendoza, L.M., Takada, H., The, S. \& Thompson, R.C. (2013) Classify plastic waste as hazardous. Nature 494: 169-171.

Rockström, J., Steffen, W., Noone, K., Persson, Å, Chapin, III, F.S., Lambin, E.F., Lenton, T.M., Scheffer, M., Folke, C., Schellnhuber, H.J., Nykvist, B., de Wit, C.A., Hughes, T., van der Leeuw, S., Rodhe, H., Sörlin, S., Snyder, P.K., Costanza, R., Svedin, U., Falkenmark, M., Karlberg, L., Corell, R.W., Fabry, V.J., Hansen, J., Walker, B., Liverman, D., Richardson, K., Crutzen, P. \& Foley, J.A. (2009) A safe operating space for humanity. Nature 461: 472-475.

Seilacher, A. (1964) Sedimentologial classification and nomenclature of trace fossils. Sedimentology 3: 253-256.

Steffen, W., Crutzen, P.J. \& McNeill, J.R., (2007) The Anthropocene: are humans now overwhelming the great forces of Nature? Ambio 36: 614-621.

Steffen, W., Persson Å., Deutsch, L., Zalasiewicz, J., Williams, M., Richardson, K., Crumley, C., Crutzen, P., Folke, C., Gordon, L., Molina, M., Ramanathan, V., Rockström, J., Scheffer, M., Schellnhuber, J., Svedin, U. (2011) The Anthropocene: from global change to planetary stewardship. Ambio 40: 739-761.

Toffler, A. (1970) Future Shock. Random House, 505 pp.

Van Lawick-Goodall, J. (1970) Tool-using in Primates and other invertebrates. 195-250 in: Advances in the study of behaviour, Volume 3. Daniel S. Lehrman (Ed.). Academic Press Inc.: New York, London. 
Wade, B. S., Pearson, P. N., Berggren, W. A. \& Pälike, H. (2011) Review and revision of Cenozoic tropical planktonic foraminiferal biostratigraphy and calibration to the geomagnetic polarity and astronomical time scale. EarthScience Reviews 104: 111-142.

Wilkinson, I. P, Poirier, C., Head, M.J., Sayer C.D., Tibby, J. in press. Micropalaeontological signatures of the Anthropocene. In Waters, C.N., Zalasiewicz, J., Williams, M. et al. (Eds.) A Stratigraphical Basis for the Anthropocene. Geol. Soc. London, Spec. Publ.

Williams, M., Zalasiewicz, J. \& Waters, C.N. (in press). Is the fossil record of complex animal behaviour a stratigraphical analogue for the Anthropocene? In Waters et al. (Eds.) A Stratigraphical Basis for the Anthropocene. Geol. Soc. London, Spec. Publ.

Wolfe, A P, Hobbs, W O, Birks, H H, Briner, J P, Holmgren, S U, Ingólfsson, Ó, Kaushal, S S, Miller, G H, Pagani, M, Saros, J E, \& Vinebrooke, R D. (2013) Stratigraphic expressions of the Holocene-Anthropocene transition revealed in sediments from remote lakes. Earth-Science Reviews 116: 17-34.

Zalasiewicz, J., Williams, M , Smith, A., Barry, T.L., Bown, P.R., Rawson, P., Brenchley, P., Cantrill, D., Coe, A.E., Cope, J.C.W., Gale, A., Gibbard, P.L., Gregory, F.J., Hounslow, M., Knox, R., Powell, P., Waters, C., Marshall, J., Oates \& Stone, P. 2008. Are we now living in the Anthropocene? GSA Today 18 (2): 4-8.

Zalasiewicz, J., Williams M, \& Waters C N. in press a. Can the Anthropocene Series be defined and recognized? In: A Stratigraphical Basis for the Anthropocene. Waters et al. (eds). Geological Society Special Publication.

Zalasiewicz, J., Kryza, R. \& Williams, M. in press b. The mineral signature of the Anthropocene. In: A Stratigraphical Basis for the Anthropocene. Waters et al. (eds). 